\title{
Effect of household bleach on the structure of the sporocyst wall of Toxoplasma gondii
}

\author{
Aurélien Dumètre $^{1,2, *}$, Jitender P. Dubey ${ }^{3}$, and David J.P. Ferguson ${ }^{4,5}$ \\ ${ }^{1}$ Aix Marseille Univ, IRD, AP-HM, SSA, VITROME, 13005 Marseille, France \\ 2 IHU-Méditerranée Infection, 13005 Marseille, France \\ ${ }^{3}$ United States Department of Agriculture, Agricultural Research Service, Beltsville Agricultural Research Center, \\ Animal Parasitic Diseases Laboratory, Building 1001, Beltsville, 20705-2350 MD, United States \\ ${ }^{4}$ Department of Biological and Medical Sciences, Faculty of Health and Life Science, Oxford Brookes University, OX3 0FL Oxford, \\ United Kingdom \\ 5 Nuffield Department of Clinical Laboratory Science, University of Oxford, John Radcliffe Hospital, OX3 9DU Oxford, United Kingdom
}

Received 25 March 2021, Accepted 19 September 2021, Published online 7 October 2021

\begin{abstract}
Toxoplasma gondii oocysts are responsible for food- and water-borne infections in humans worldwide. They are resistant to common chemical disinfectants, including chlorinated products, presumably due to the structure and molecular nature of the oocyst wall but also the sporocyst wall. In this study, we used fluorescence microscopy and transmission electron microscopy to characterise the structure of both the oocyst and sporocyst walls, exposed to household bleach. Bleach removed the outer layer of the oocyst wall and the outer layer of the wall of sporocysts exposed due to rupture of the oocyst wall. The loss of the outer sporocyst wall layer was associated with a decrease in its autofluorescence, which can be linked to the degradation of dityrosine cross-link proteins, and loss of Maclura pomifera lectin-reactive glycoproteins. This study suggests that the inner layers of the oocyst and sporocyst walls are the main structures responsible for the resistance of the parasite to household bleach.
\end{abstract}

Key words: Toxoplasma gondii, Oocyst, Sporocyst, Wall, Bleach, Resistance.

Résumé - Effet de l'eau de Javel à usage domestique sur la structure de la paroi du sporocyste de Toxoplasma gondii. Les oocystes de Toxoplasma gondii sont responsables chez l'homme d'infections cosmopolites d'origine alimentaire et hydrique. Ils sont résistants aux désinfectants chimiques usuels, notamment aux produits chlorés, vraisemblablement en raison de la structure et de la nature moléculaire de la paroi de l'oocyste mais aussi de celle du sporocyste. Dans cette étude, nous avons utilisé la microscopie à fluorescence et la microscopie électronique à transmission pour caractériser la structure de la paroi des oocystes et des sporocystes exposés à l'eau de Javel à usage domestique. L'eau de Javel élimine la couche externe de la paroi de l'oocyste et la couche externe de la paroi des sporocystes exposés en raison de la rupture de la paroi de l'oocyste. La perte de la couche externe de la paroi du sporocyste est associée à une diminution de son autofluorescence, qui peut être liée à la dégradation de polymères protéiques de dityrosine, et à une perte des glycoprotéines réactives à la lectine Maclura pomifera. Cette étude suggère que les couches internes des parois de l'oocyste et du sporocyste sont les principales structures responsables de la résistance du parasite à l'eau de Javel à usage domestique.

\section{Introduction}

Toxoplasma gondii is a common protozoan parasite of birds and mammals worldwide. It is estimated that nearly one third of the global human population is infected by the parasite. Humans generally become infected by either ingesting tissue cysts in undercooked meat or oocysts present in water and food contaminated with cat faeces. Infections may range from asymptomatic to severe ocular, cerebral or multivisceral symptoms depending on parasite and host factors [17]. Compared to

\footnotetext{
*Corresponding author: aurelien.dumetre@univ-amu.fr
}

immunocompetent adults, congenitally infected children and immunocompromised people are particularly at risk of clinical toxoplasmosis. In the absence of specific drug treatments and human vaccines, preventing the transmission of the parasite is essential to reduce the burden of the infection [18].

Oocysts are resistant to various environmental conditions and inactivation procedures [21]. They can remain infective for weeks in surface water and moist soils at $4-25^{\circ} \mathrm{C}$ and on salads or berries stored at $2-8^{\circ} \mathrm{C}$. Though oocysts can be killed in a few minutes above $60^{\circ} \mathrm{C}$, they withstand common household products such as bleach and detergents, and most chemical disinfectants used by the drinking water industry such as 
chlorine dioxide and ozone. Recent studies indicate that the bilayered oocyst and sporocyst walls act as robust and almost hermetic barriers to protect the sporozoites from the deleterious effect of chemical disinfectants, in particular chlorinated products [9]. However, the structural and molecular basis for this resistance is not fully understood. Here, we used fluorescence and transmission electron microscopy (TEM) techniques to gain further insights on the structure of $T$. gondii oocyst walls, especially at the sporocyst level, exposed to household bleach.

\section{Materials and methods Oocyst production}

Oocysts of the strains $\mathrm{ME} 49$ (type II) or $\mathrm{TgCgCa} 2$ (atypical) of $T$. gondii were used throughout the experiments. They were harvested from faeces of cats 6-8 days after feeding infected mouse tissues as described in [6]. Oocysts were collected by flotation at $4^{\circ} \mathrm{C}$ from cat faeces on a 1.15 specific gravity sucrose solution, washed in distilled water and then resuspended in $10 \mathrm{~mL}$ of an aqueous solution containing $2 \%$ $\mathrm{H}_{2} \mathrm{SO}_{4}$. They were then allowed to sporulate at room temperature (RT 20-22 $\mathrm{C}$ ) for 7 days under adequate aeration and gentle continuous shaking. Oocysts were stored in a $2 \%$ $\mathrm{H}_{2} \mathrm{SO}_{4}$ aqueous solution at $4^{\circ} \mathrm{C}$ until use. For experiments, oocysts were washed twice in distilled water and once in PBS at $5000 \mathrm{~g}$ for $5 \mathrm{~min}$ to remove sulphuric acid.

\section{Bleach and/or heat treatment}

Oocysts in $100 \mu \mathrm{L}$ PBS were sonicated in an Elmasonic $\mathrm{S} 30 \mathrm{H}$ water bath (Elma, Singen, Germany) in a plastic $1.5-\mathrm{mL}$ microtube for $7 \mathrm{~min}$ at RT. Under these conditions, sonication resulted in a mixture of microscopically intact oocysts and free intact sporocysts. Individual suspensions were then exposed to bleach or heat, or bleach and heat. For bleach treatment, parasites were incubated in $1 \mathrm{~mL}$ of a diluted household bleach solution (Lacroix Javel, Colgate-Palmolive, Bois-Colombes, France) containing 3\% sodium hypochlorite in PBS for $30 \mathrm{~min}$ at $4^{\circ} \mathrm{C}$. Parasites were then washed three times in PBS to remove bleach before further experiments. For heat treatment, either normal or bleach-treated parasite suspensions were suspended in $500 \mu \mathrm{L}$ PBS and incubated in a dry block heater for $10 \mathrm{~min}$ at $80^{\circ} \mathrm{C}$. Then, parasite suspensions were cooled at RT for $20 \mathrm{~min}$ prior to being stored at $4^{\circ} \mathrm{C}$ until further experiments.

\section{Transmission electron microscopy}

To evaluate the effects of bleach and/or heat treatments on the ultrastructure of oocyst and sporocyst walls, suspensions containing either untreated or treated parasites were fixed in $2.5 \%$ glutaraldehyde in $0.1 \mathrm{M}$ PBS buffer and processed for routine electron microscopy [6]. In summary, the samples were post-fixed in osmium tetroxide, dehydrated in ethanol, treated with propylene oxide and embedded in Spurr's epoxy resin. Thin sections were cut and stained with uranyl acetate and lead citrate prior to examination in a Jeol 1200EX electron microscope.

\section{Autofluorescence and lectin labelling of the sporocyst wall}

The autofluorescence (AF) intensity under UV excitation and lectin-binding pattern of the sporocyst wall were evaluated as an indirect approach to evaluate the effect of bleach and/or heat on the wall structure and molecules such as tyrosine-rich protein cross-links and glycoproteins. For this, untreated or treated parasite suspensions were reacted with an FITC-conjugated Maclura pomifera lectin (MPL) (Vector labs) at $20 \mu \mathrm{g} / \mathrm{mL}$ in $100 \mu \mathrm{L}$ PBS for $90 \mathrm{~min}$ at $37^{\circ} \mathrm{C}$ as described in [3]. This lectin has a preferential specificity for $\alpha$-linked $N$-acetylgalactosamine (GalNAc) structures and can label the sporocyst wall [3, 7]. Following three washes in PBS at $5000 \times g$ for $5 \mathrm{~min}$, samples were mounted and examined on a BX51 microscope (Olympus, France) equipped with a CCD camera (XC30, Olympus), 40× and $100 \times$ objectives (Olympus), and suitable epifluorescence filters for $\mathrm{AF}\left(\lambda_{\mathrm{ex}}=330-385 \mathrm{~nm} / \lambda_{\mathrm{em}}=420 \mathrm{~nm}\right)$ and FITC $\left(\lambda_{\mathrm{ex}}=395-475 \mathrm{~nm} / \lambda_{\mathrm{em}}=498 \mathrm{~nm}\right)$ detection. Bright field, AF, and FITC images of parasite suspensions over $\sim 20$ randomly selected microscopical fields per treatment condition were acquired at a constant exposure time of $200 \mathrm{~ms}$ as grey scale images using Cell ${ }^{\mathrm{A}}$ software (Olympus, France) and analysed using ImageJ $1.46 \mathrm{~m}$ (https://imagej.nih.gov). AF relative intensity of the sporocyst wall was quantified in free sporocysts as described in Figure 2A. AF quantification of sporocysts within intact oocysts was not possible because of the superimposition of the sporocyst and oocyst walls. For the MPL-binding assay, sporocysts were classified as MPL-positive or MPL-negative based on the FITC fluorescence of their wall.

\section{Results and discussion}

TEM experiments revealed that, in intact oocysts, penetration of fixatives is prevented, resulting in collapse of the sporocysts (Fig. 1A). The typical bilayered structure of the walls of untreated T. gondii oocysts (Fig. 1B) and sporocysts (Fig. 1C) consists of a thin outer layer and a thicker inner one. The sporocyst wall has a continuous thin outer electron dense layer, while the inner layer consists of four plates connected to each other by thickened sutures (Fig. 1C). The walls of sporocysts, whether protected or not by the oocyst wall, were similar in structure. Following heating at $80^{\circ} \mathrm{C}$, both the oocyst (Fig. 1D) and sporocyst (Fig. 1E) walls retained their bilayered structure. However, after exposure to household bleach, the outer layer of the oocyst wall was stripped off, but not the inner one (Fig. 1F). Sporocysts found in intact oocysts retained their bilayered wall (Fig. 1G). In contrast, bleach removed the outer wall layer of free sporocysts, but had no marked effect on the structure of the inner layer and sutures (Fig. 1H). Similar observations were made in bleach then heat-treated oocysts and sporocysts (Figs. 1I-1K). The effects of treatment with household bleach were then specifically evaluated on the molecular properties of the wall of free sporocysts. AF intensity of free sporocysts significantly decreased following bleach, but not heat treatment (Figs. 2A and 2B). This reduction was concomitant with the loss of MPL labelling of the sporocyst wall surface (Fig. 3). Combined with the TEM observations, these results indicate that $\mathrm{AF}$ reduction and degradation of MPL-reactive glycoproteins of the wall of free sporocysts 

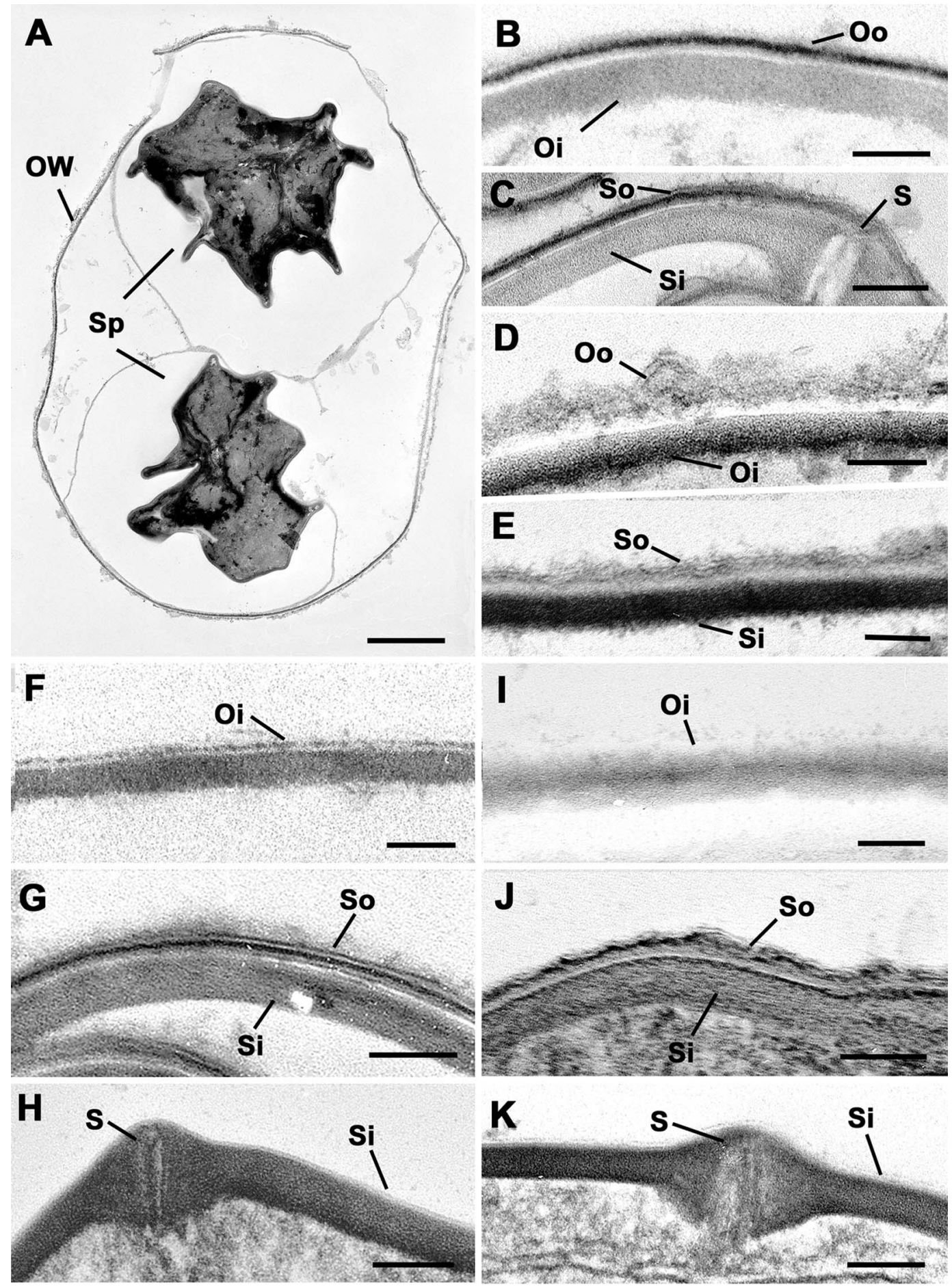

Figure 1. Electron micrographs of the walls of oocysts and sporocysts undergoing various treatments. A bar represents $1 \mu \mathrm{m}$ in $\mathrm{A}$ and $100 \mathrm{~nm}$ in the other micrographs. (A) Section through an intact oocyst showing the two collapsed sporocysts (Sp). OW - oocyst wall. (B) Detail of an untreated oocyst showing the outer (Oo) and inner (Oi) layers of the oocyst wall. (C) Detail of an untreated oocyst showing the outer (So) layer and the plates of the inner ( $\mathrm{Si}$ ) layer of the sporocyst wall connected by a thicken suture (S). (D) Enlargement of a heat-treated oocyst showing the retention of both the outer (Oo) and inner (Oi) layers oocyst wall. (E) Enlargement of a heat-treated oocyst showing the retention of both the outer ( $\mathrm{So}$ ) and inner ( $\mathrm{Si}$ ) layers of the sporocyst wall. (F) Detail of the wall of an oocyst after treatment with bleach showing the inner (Oi) layer, but loss of the outer layer of the oocyst wall. (G) Bleach-treated intact oocyst showing the retention of both the outer (So) and inner (Si) layer of the sporocyst wall. $(\mathrm{H})$ Naked sporocyst treated with bleach showing the loss of the outer layer, but retention of the inner ( $\mathrm{Si}$ ) layer of the sporocyst wall. S - suture. (I) Detail of an oocyst treated with bleach and heating showing the inner (Oi) layer, but loss of the outer layer of the oocyst wall. (J) Bleach and heat treated intact oocyst showing the retention of both the outer (So) and inner (Si) layer of the sporocyst wall. (K) Naked sporocyst treated with bleach and heating showing the loss of the outer layer, but retention of the inner ( $\mathrm{Si}$ ) layer of the sporocyst wall. S - suture. 
A
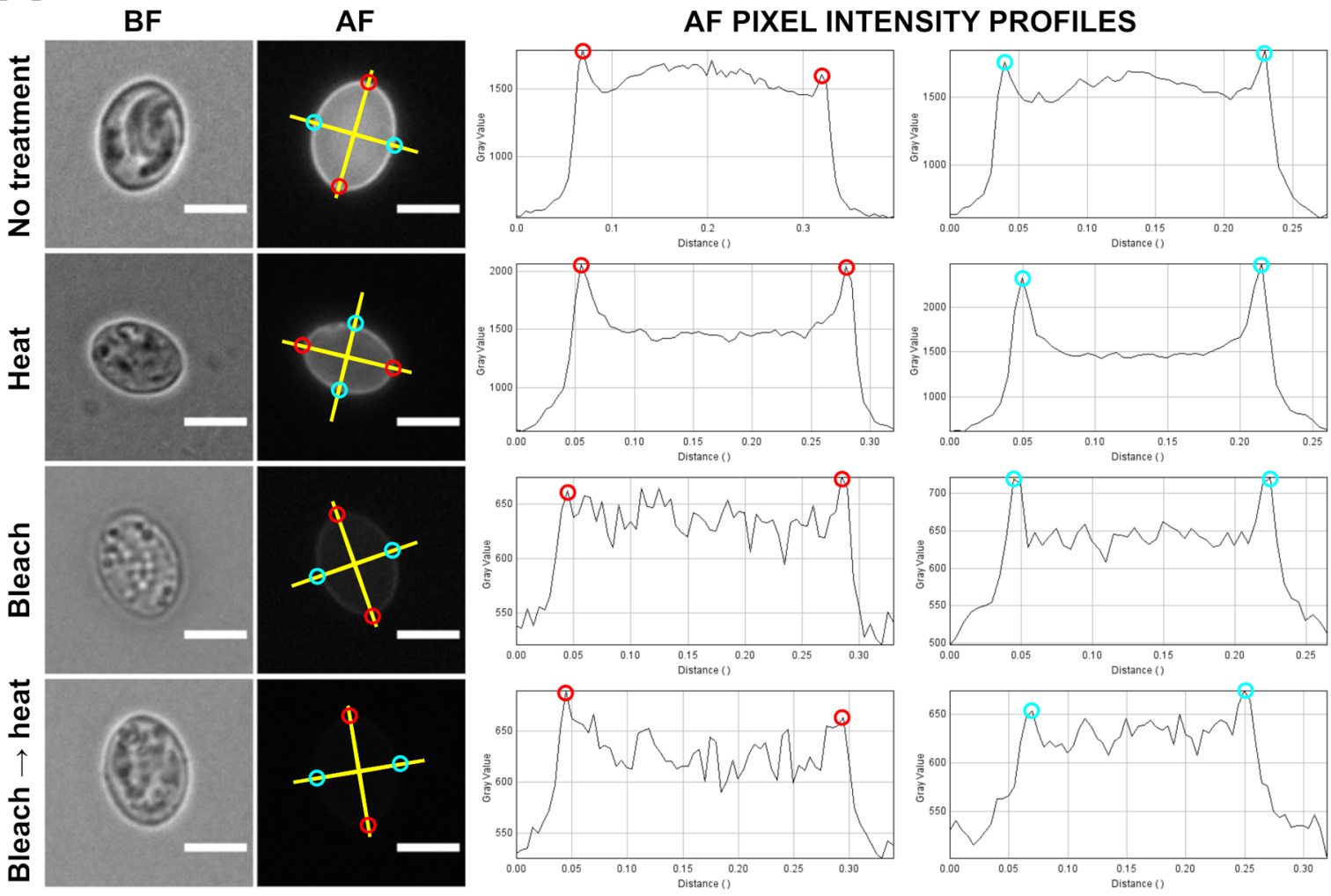

B

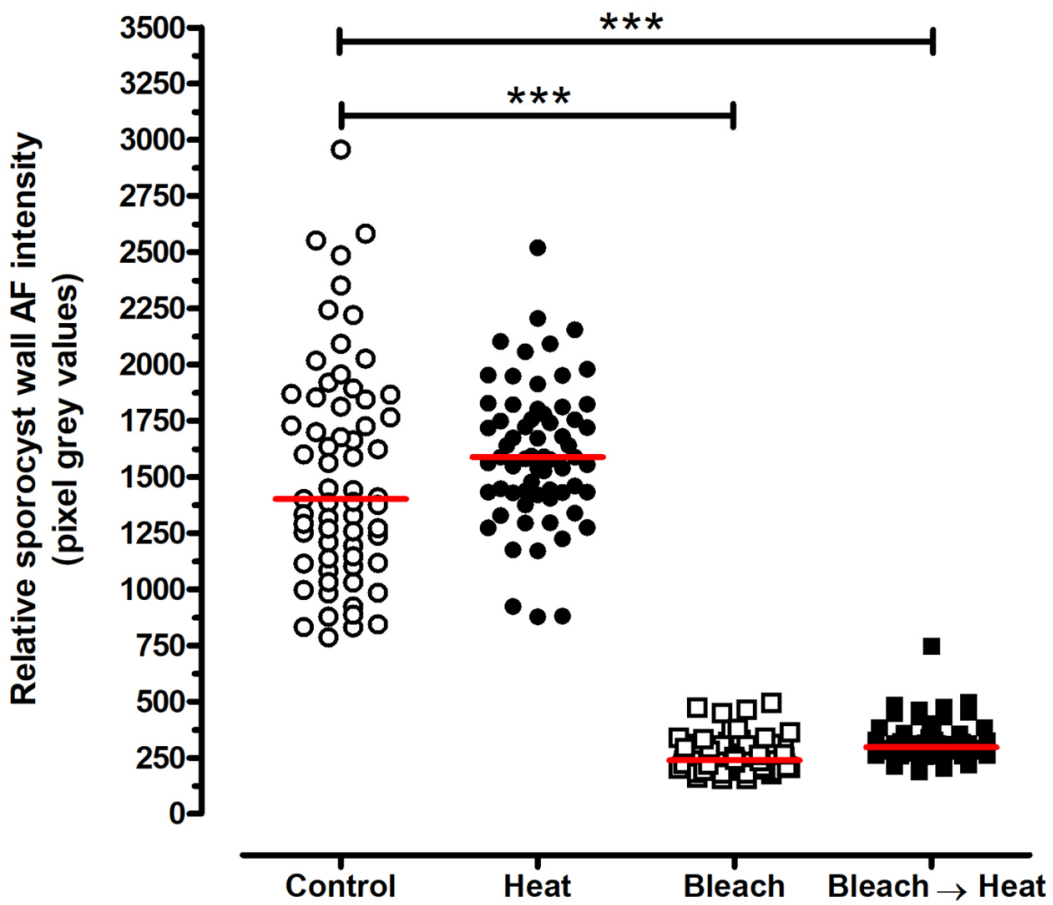

Figure 2. Autofluorescence (AF) wall properties of untreated, bleached and/or heated free Toxoplasma gondii sporocysts. (A) Relative AF intensity was quantified by recording pixel grey values along two straight lines (in yellow) arbitrarily set up across the length and width of each sporocyst. The corresponding plot profiles were generated on ImageJ to determine pixel grey values at the intercepts with the sporocyst wall (red and cyan circles). Following normalisation with regard to background grey value of each image, a mean pixel grey value was calculated for each sporocyst and then plotted as a function of parasite treatment condition using Graph Pad Prism 5.03 software. (B) Distribution of the relative AF intensity of the sporocyst wall as a function of treatment. The red line is the median of the distribution $(n=65$ sporocysts analysed per condition). $* * * p<0.001$ (Kruskal-Wallis test). 


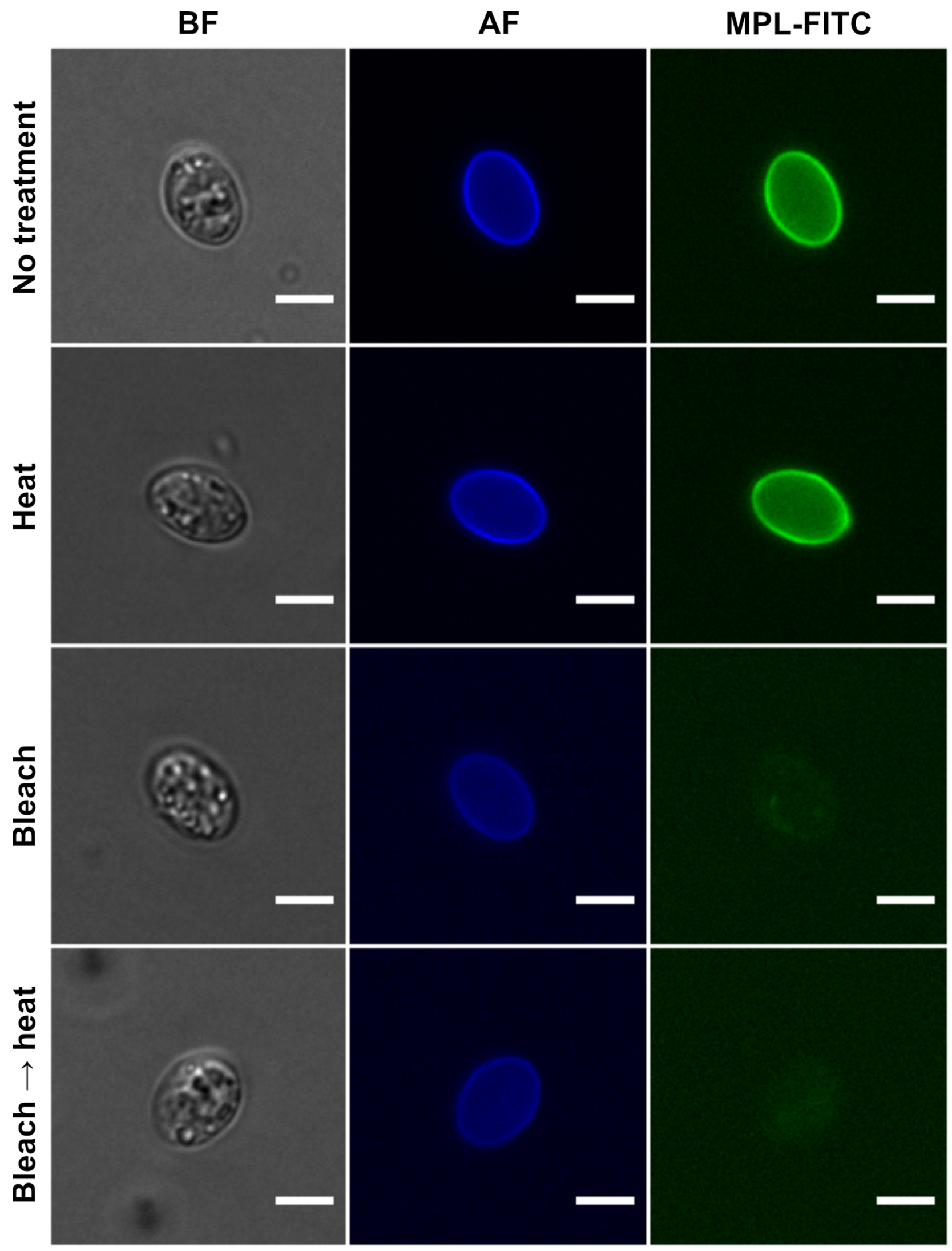

Figure 3. Maclura pomifera lectin-binding pattern of the wall of untreated, bleached and/or heated free Toxoplasma gondii sporocysts. BF, bright field; AF, autofluorescence; MPL-FITC, Maclura pomifera coupled to FITC. Bar represents $5 \mu \mathrm{m}$. 
following bleach treatment appear to be linked to the removal of the outer sporocyst wall layer.

The exact nature, location, and functions of the molecules composing the oocyst and sporocyst walls of $T$. gondii and related coccidian parasites remain largely unknown (reviewed in $[2,9,15])$. A general model indicates that both walls are highly proteinaceous with a lipid coating, while sugar polymers are restricted to the inner oocyst wall layer. A common feature across coccidian oocysts is the AF of their walls under UV excitation [13]. In Eimeria maxima and E. tenella oocysts, tyrosine-rich proteins are associated with the development of the inner layer of the oocyst wall $[1,2,8,15]$ and of the sporocyst wall [22]. These proteins are prone to form dityrosine bonds that make the oocyst and sporocyst walls autofluorescent. Bleach can strip the outer layer of the Eimeria oocyst wall, but does not markedly affect the structure and AF of the inner oocyst wall layer nor of the wall of encased sporocysts [1]. Tyrosine-rich proteins identified in Eimeria parasites have no homologues in $T$. gondii $[2,9,15]$. In this parasite, several other tyrosine-rich proteins have been detected in the oocyst and sporocyst walls [2, 9-11]. They likely contribute to AF of both walls; however, it is not clear where they are located. Our results and previous studies show that bleach strips off the T. gondii oocyst outer wall layer, reduces AF of the oocyst wall, and decreases the relative abundance of tyrosine-rich proteins in oocyst wall fractions analysed by mass spectrometry $[6,11]$. The sporocyst wall can retain its bilayered structure and AF as long as the oocyst wall remains resistant to bleach infiltration. In contrast, openings in or removal of the oocyst wall and then bleach treatment eliminate the outer sporocyst wall layer and reduce the sporocyst wall AF. These observations suggest that, in $T$. gondii, bleach leads to the degradation of most AF-associated proteins, putatively tyrosine-rich proteins, in both the outer layers of the oocyst and sporocyst walls. It has been shown that the $T$. gondii-specific tyrosine-rich protein TyRP1, which is found in the oocyst wall but not in the sporocyst wall, is sensitive to bleach [10]. It is likely that other wall molecules contribute to the resistance of $T$. gondii and its relatives to environmental factors. In particular, the role of cysteine-rich proteins, lectin-reactive glycoproteins, and $\beta-1,3$ glucans, which have been found in the oocyst and/or sporocyst walls of $T$. gondii and/or Eimeria parasites remains to be explored [3, 7, 9, 12, 15].

In conclusion, bleach can strip off the outer wall layers of both $T$. gondii oocysts and free sporocysts. These modifications are associated with the reduction of autofluorescent macromolecular complexes, presumably dityrosine cross-linked, and, at the sporocyst wall level, of glycoproteins, yet to be identified. Our results confirm the role of the inner oocyst wall layer in the structural resistance of $T$. gondii oocysts to household bleach [6] and highlight the unexpected contribution of the inner sporocyst wall layer as a second protective barrier for sporozoites in case of rupture of the oocyst wall and loss of the sporocyst outer wall layer. It is not known whether fractured oocysts can survive in environmental samples; however, experimental data indicate that free sporocysts stored at $4^{\circ} \mathrm{C}$ in $2 \%$ $\mathrm{H}_{2} \mathrm{SO}_{4}$ and PBS solutions can remain infectious for 20 days [4] and 5 months [19], respectively. Interestingly, free sporocysts are a major infective stage in the life cycle of the closely related coccidian of the genus Sarcocystis [16]. Sarcocystis neurona and $T$. gondii have a similar sporocyst wall structure [14] and AF properties [13]. As suggested for T. gondii, this structural organisation could help $S$. neurona sporocysts withstand environmental conditions and chemical disinfectants [5], without the assistance of the oocyst wall. Future progress in the characterisation of the oocysts of $T$. gondii and its coccidian relatives should help to identify the molecules and substructures, especially at the sporocyst and oocyst wall levels, that can make these parasites so resistant to adverse environmental conditions [20].

Acknowledgements. This study was supported in part by AixMarseille University and the Région Provence-Alpes-Côte d'Azur ToxoLand grant (No. 2014-02623). The authors report that they have no conflicts of interest.

\section{References}

1. Belli SI, Wallach MG, Luxford C, Davies MJ, Smith NC. 2003. Roles of tyrosine-rich precursor glycoproteins and dityrosineand 3,4-dihydroxyphenylalanine-mediated prtoein cross-linking in development of the oocyst wall in the coccidian parasite Eimeria maxima. Eukaryotic Cell, 2, 456-464.

2. Belli SI, Smith NC, Ferguson DJP. 2006. The coccidian oocyst: a tough nut to crack! Trends in Parasitology, 22, 416-423.

3. Bushkin GG, Motari E, Magnelli P, Gubbels MJ, Dubey JP, Miska KB, Bullitt E, Costello CE, Robbins PW, Samuelson J. 2012. $\beta$-1,3-glucan, which can be targeted by drugs, forms a trabecular scaffold in the oocyst walls of Toxoplasma and Eimeria. Mbio, 3, e00258-12.

4. Christie E. 1977. Ultrastructure and optimal conditions necessary for the excystation of Toxoplasma gondii oocysts and sporocysts. $\mathrm{Ph}$. D. dissertation. USA: The Ohio State University.

5. Dubey JP, Howe DK, Furr M, Saville WJ, Marsh AE, Reed SM, Grigg ME. 2015. An update on Sarcocystis neurona infections in animals and equine protozoal myeloencephalitis (EPM). Veterinary Parasitology, 209, 1-42.

6. Dumètre A, Dubey JP, Ferguson DJP, Bongrand P, Azas N, Puech P-H. 2013. Mechanics of the Toxoplasma gondii oocyst wall. Proceedings of the National Academy of Sciences of the United States of America, 110, 11535-11540.

7. Fabian BT, Lepenies B, Schares G, Dubey JP, Spano F, Seeber F. 2021. Expanding the known repertoire of C-type lectin receptors binding to Toxoplasma gondii oocysts using a modified highresolution immunofluorescence assay. Msphere, 6, e01341-20.

8. Ferguson DJP, Belli SI, Smith NC, Wallach MG. 2003. The development of the macrogamete and oocyst wall of Eimeria maxima: immuno-light and electron microscopy. International Journal for Parasitology, 33, 1329-1340.

9. Freppel W, Ferguson DJP, Shapiro K, Dubey JP, Puech P-H, Dumètre A. 2019. Structure, composition, and roles of the Toxoplasma gondii oocyst and sporocyst walls. Cell Surface, 5, 100016.

10. Fritz HM, Conrad PA. 2018. Antibodies to the surface of Toxoplasma gondii oocysts and methods of use thereof. US patent US20180017557A1. https://patentimages.storage.googleapis.com/ 5e/53/ee/c05ef06c82e632/US10429386.pdf.

11. Fritz HE, Bowyer PW, Bogyo M, Conrad PA, Boothroyd JC. 2012. Proteomic analysis of fractionated Toxoplasma oocysts reveals clues to their environmental resistance. PLoS One, 7, e29955. 
12. Jonscher E, Erdbeer A, Günther M, Kurth M. 2015. Two COWP-like cysteine rich proteins from Eimeria nieschulzi (coccidia, apicomplexa) are expressed during sporulation and involved in the sporocyst wall formation. Parasites \& Vectors, $8,395$.

13. Lindquist HDA, Bennett JW, Hester JD, Ware MW, Dubey JP, Everson WV. 2003. Autofluorescence of Toxoplasma gondii and related coccidian oocysts. Journal of Parasitology, 89, $865-867$.

14. Lindsay DS, Mitchell S, Vianna MC, Dubey JP. 2004. Sarcocystis neurona (Protozoa; Apicomplexa): description of oocysts, sporocysts, sporozoites, excystation, and early development. Journal of Parasitology, 90, 461-465.

15. Mai K, Sharman PA, Walker RA, Katrib M, De Souza D, McConville MJ, Wallach MG, Belli SI, Ferguson DJP, Smith NC. 2009. Oocyst wall formation and composition in coccidian parasites. Memórias do Instituto Oswaldo Cruz, 104, 281-289.

16. Mehlhorn H, Heydorn AO. 1978. The sarcosporidia (Protozoa, Sporozoa): life cycle and fine structure. Advances in Parasitology, 16, 43-91.

17. Mukhopadhyay D, Arranz-Solis D, Saeij JP. 2020. Influence of the host and parasite strain on the immune response during
Toxoplasma infection. Frontiers in Cellular and Infection Microbiology, 10, 580425.

18. Robert-Gangneux F, Dardé M-L. 2012. Epidemiology of and diagnostic strategies for toxoplasmosis. Clinical Microbiology Reviews, 25, 264-296.

19. Rousseau A, Escotte-Binet S, La Carbona S, Dumètre A, Chagneau S, Favennec L, Kubina S, Dubey JP, Majou D, BigotClivot A, Villena I, Aubert D. 2019. Toxoplasma gondii oocyst infectivity assessed using a sporocyst-based cell culture assay combined with quantitative PCR for environmental applications. Applied and Environmental Microbiology, 85, e01189-19.

20. Samuelson J, Bushkin GG, Chatterjee A, Robbins PW. 2013. Strategies to discover the structural components of cyst and oocyst walls. Eukaryotic Cell, 12, 1578-1587.

21. Shapiro K, Bahia-Oliveira L, Dixon B, Dumètre A, de Wit LA, VanWormer E, Villena I. 2019. Environmental transmission of Toxoplasma gondii: oocysts in water, soil and food. Food and Waterborne Parasitology, 15, e00049.

22. Walker RA, Niepceron A, Ramakrishnan C, Sedano L, Hehl AB, Brossier F, Smith NC. 2016. Discovery of a tyrosine-rich sporocyst wall protein in Eimeria tenella. Parasites \& Vectors, 9, 124 .

Cite this article as: Dumètre A, Dubey JP \& Ferguson DJ. 2021. Effect of household bleach on the structure of the sporocyst wall of Toxoplasma gondii. Parasite 28, 68 .

\section{(0) PARASTE}

An international open-access, peer-reviewed, online journal publishing high quality papers on all aspects of human and animal parasitology

Reviews, articles and short notes may be submitted. Fields include, but are not limited to: general, medical and veterinary parasitology; morphology, including ultrastructure; parasite systematics, including entomology, acarology, helminthology and protistology, and molecular analyses; molecular biology and biochemistry; immunology of parasitic diseases; host-parasite relationships; ecology and life history of parasites; epidemiology; therapeutics; new diagnostic tools.

All papers in Parasite are published in English. Manuscripts should have a broad interest and must not have been published or submitted elsewhere. No limit is imposed on the length of manuscripts.

Parasite (open-access) continues Parasite (print and online editions, 1994-2012) and Annales de Parasitologie Humaine et Comparée (1923-1993) and is the official journal of the Société Française de Parasitologie. 